ACADEMIA ROMÂNĂ

Revue Roumaine de Chimie

http://web.icf.ro/rrch/
Rev. Roum. Chim.

2020, 65(7-8), 673-676

DOI: $10.33224 /$ rrch.2020.65.7-8.03

Papers

\title{
SYNTHESIS AND STRUCTURE OF 6-DIPHENYLPHOSPHINOACENAPHTH-5-YL BISMUTH COMPOUNDS
}

\author{
Sinas FURAN, Emanuel HUPF, Enno LORK and Jens BECKMANN* \\ Institut für Anorganische Chemie und Kristallographie, Universität Bremen, Leobener Straße 7, 28359 Bremen, Germany
}

The di- and tri-substituted arylbismuth compounds $\mathrm{R}_{2} \mathrm{BiCl}$ and $\mathrm{R}_{3} \mathrm{Bi}(\mathrm{R}=6$-diphenylphosphinoacenaphth-5yl) were prepared and fully characterized. Both compounds contain intramolecularly coordinating P-donor atoms that provide electron density to the bismuth atoms.

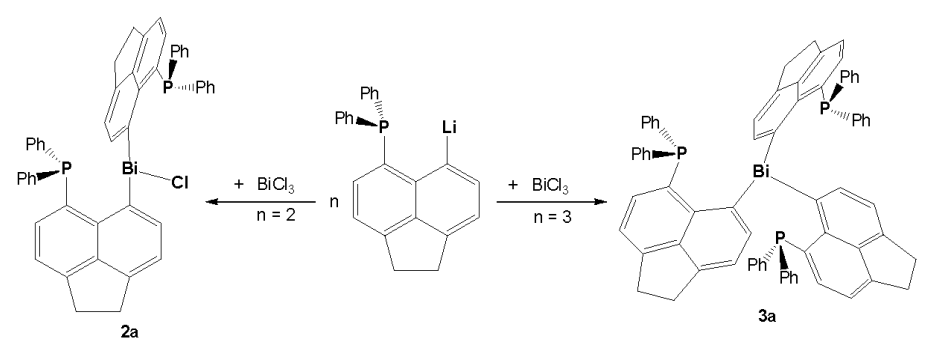

\section{INTRODUCTION}

There is a growing interest in arylbismuth compounds containing intramolecularly coordinating donor ligands, which are able to block potential coordination sites at the bismuth atom and to (partly) compensate the inherent Lewis acidity. ${ }^{1}$ Alternatively, the donor ligands may also bind to transition metal ions giving rise to interesting complexes that involve metal bismuth interactions. The vast majority of these ligands possess Ndonors, ${ }^{2-8}$ whereas as P-donors are only occasionally encountered. ${ }^{9-15}$ As part of our research programme on peri-substituted scaffolds, we recently prepared the monoarylbismuth dichloride $\mathrm{RBiCl}_{2}$ (1a, $\mathrm{R}=$ 6-diphenylphosphinoacenaphth-5-yl), the analogous arylantimony dichloride $\mathrm{RSbCl}_{2} \quad(\mathbf{1 b})^{16}$ as well as the diarylantimony chloride $\mathrm{R}_{2} \mathrm{SbCl}(\mathbf{2 b})$ and the triarylantimony $\quad \mathrm{R}_{3} \mathrm{Sb} \quad(\mathbf{3 b}) .{ }^{17}$ The latter two compounds were also used as (coordination noninnocent) ligands towards late transitions metals. In an effort to complete the series of bismuth compounds, we now also report on the synthesis and structure of diarylbismuth chloride $\mathrm{R}_{2} \mathrm{BiCl}$ (2a) and the triarylbismuth $\mathrm{R}_{3} \mathrm{Bi}$ (3a), which also hold potential as ligands for the preparation of transition metal complexes.

\section{RESULTS AND DISCUSSION}

The synthesis of 2a and 3a was achieved by the stoichiometry controlled reaction between the aryl lithium $\mathrm{RLi}$ and $\mathrm{BiCl}_{3}$ at $-78^{\circ} \mathrm{C} \quad(\mathrm{R}=6-$ diphenylphosphinoacenaphth-5-yl, Scheme 1). ${ }^{18}$

\footnotetext{
${ }^{*}$ Correspondence to Jens Beckmann: e-mail: j.beckmann@uni-bremen.de
} 
The products $\mathbf{2 a}$ and $\mathbf{3 a}$ were obtained as pale yellow crystalline solids in 85 and $73 \%$ yield, respectively. The molecular structures of $\mathbf{2 a}$ and $\mathbf{3 a}$ are shown in Figure 1. There are two crystallographically independent, yet very similar conformers of $\mathbf{2 a}$ in the crystal lattice. In both compounds, the spatial arrangement of the $\mathrm{Bi}$ atoms is trigonal pyramidal when bearing in mind the first coordination sphere.

In addition, there are significant $\mathrm{Bi} \cdots \mathrm{P}$ periinteractions that are shorter than the sum of van der Waals radii. One $\mathrm{Bi} \cdots \mathrm{P}$ bond length of $\mathbf{2 a}$ [2.8990(13) $\AA,(2.8614(14) \AA)]$ is significantly shorter than the other [3.3555(13) $\AA$, (3.2704(12) $\AA)$ ] and slightly longer than the $\mathrm{Bi} \cdots \mathrm{P}$ distance of 1a $(2.7696(8) \AA) .{ }^{16}$ The $\mathrm{Bi} \cdots \mathrm{P}$ bond lengths of 3a (3.2166(7), 3.2660(5), 3.2745(7) $\AA$ ) are between the respective distances found for $\mathbf{2 a}$. Overall, the bond situation closely resembles that of the $\mathrm{Sb} \cdots \mathrm{P}$ bond lengths of $\mathbf{1 b}(2.8080(9) \AA),{ }^{16} \mathbf{2 b}$ (2.7738(8), $3.2660(7) \AA)$ and 3b (3.1713(8), 3.2293(7), $3.2427(9) \AA)^{17}$ as well as of the related $\mathrm{R}_{3}{ }_{3} \mathrm{Bi}$ species $\left(\mathrm{R}^{\prime}=6\right.$-di-iso-propylphosphinoacenaphth5-yl; 3.218(3)-3.279(4) $\AA$ ). ${ }^{19}$

Compounds 2a and 3a are soluble in common organic solvents, such as dichloromethane, tetrahydrofuran and toluene. The ${ }^{31} \mathrm{P}\left\{{ }^{1} \mathrm{H}\right\}$-NMR spectra $\left(\mathrm{CD}_{2} \mathrm{Cl}_{2}\right)$ of $\mathbf{2 a}$ and 3a show single resonances at $\delta=-20.9 \mathrm{ppm}$ and $-30.6 \mathrm{ppm}$, respectively, indicating magnetic equivalence of the 6-diphenylphosphinoacenaphth-5-yl groups in solution at room temperature. These values compare well with those of the antimony analogues $\mathbf{2 b}(\delta=-20.3)$ and $\mathbf{3 b}(\delta=-26.8 \mathrm{ppm})$.

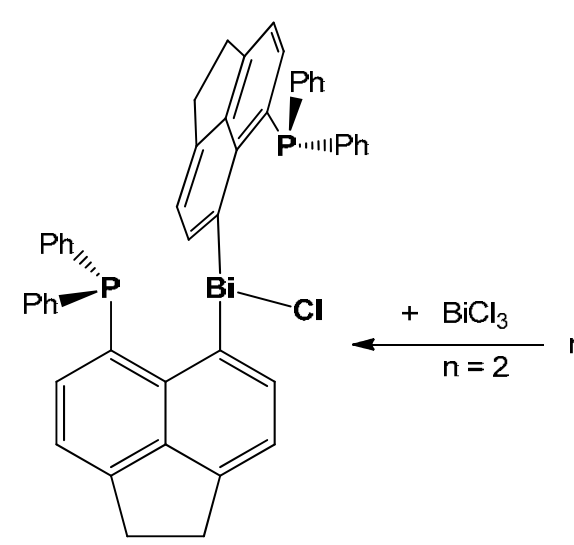

$\mathbf{2 a}$

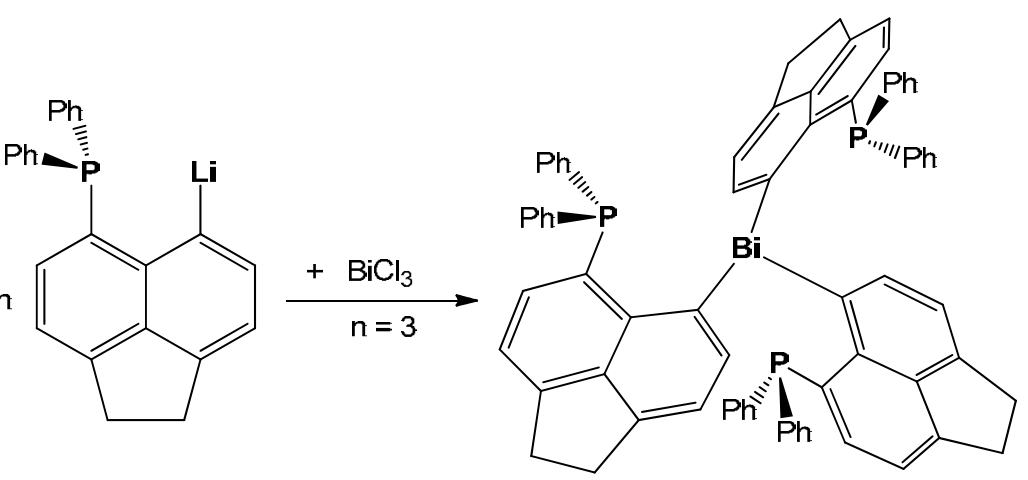

$3 \mathbf{a}$

Scheme 1 - Synthesis of $\mathbf{2 a}$ and $\mathbf{3 a}$.
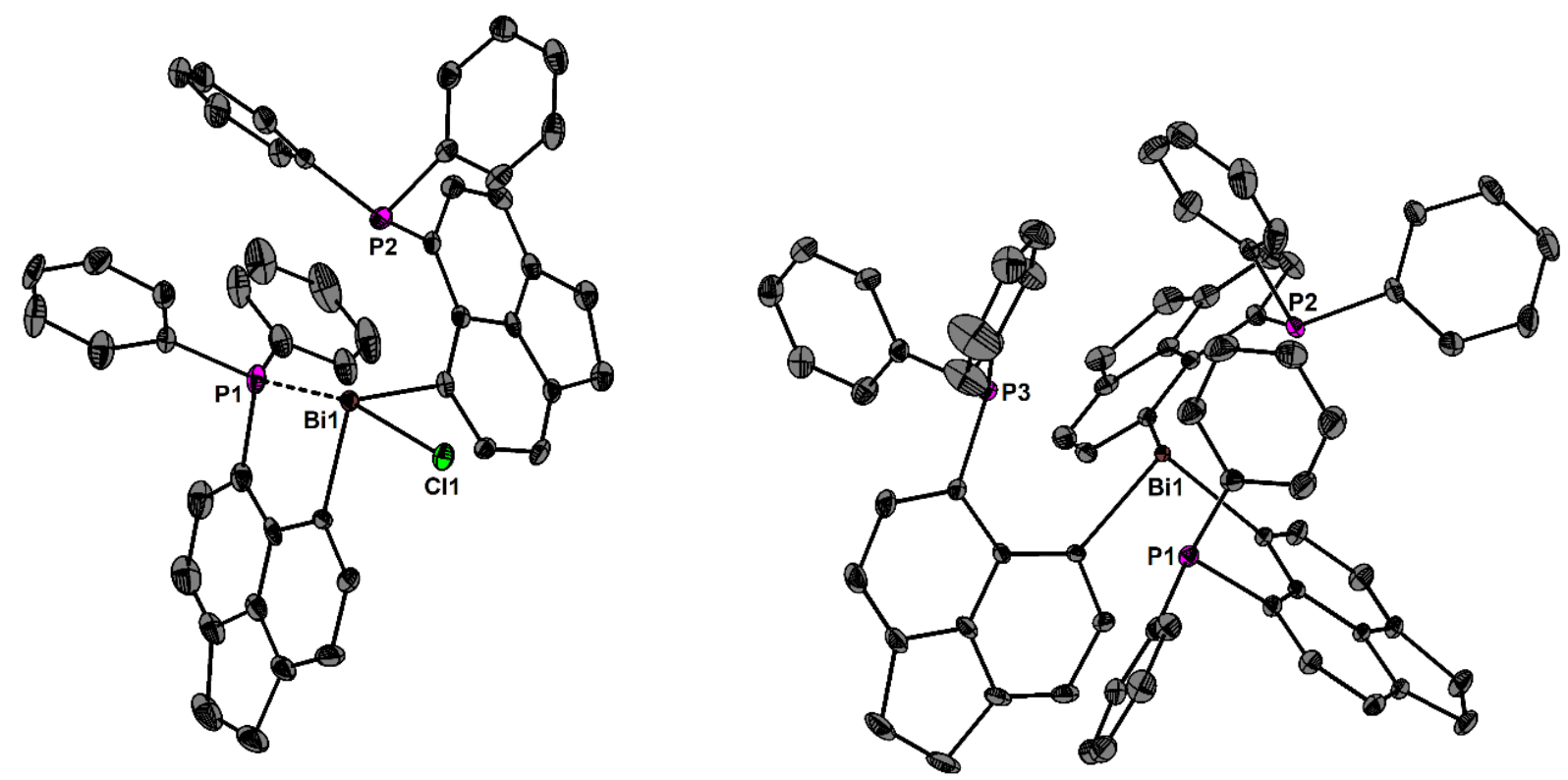

Fig. 1 - Molecular structures of $\mathrm{R}_{2} \mathrm{BiCl}$ (2a, left) and $\mathrm{R}_{3} \mathrm{Bi}$ (3a, right) showing 50\% probability ellipsoids ( $\mathrm{R}=6$-diphenylphosphinoacenaphth-5-yl). 


\section{EXPERIMENTAL}

General. Reagents were obtained commercially (SigmaAldrich, Germany) and were used as received. Dry solvents were collected from a SPS $800 \mathrm{mBraun}$ solvent system. The starting material 5-bromo-6-diphenylphosphinoacenaphthene was prepared according to literature procedures. ${ }^{20}{ }^{1} \mathrm{H}-$, ${ }^{13} \mathrm{C}\left\{{ }^{1} \mathrm{H}\right\}$ - and ${ }^{31} \mathrm{P}\left\{{ }^{1} \mathrm{H}\right\}$-NMR spectra were recorded at room temperature (unless otherwise stated) using Bruker Avance 360 and Neo 600 spectrometer and are referenced to tetramethylsilane $\left({ }^{1} \mathrm{H},{ }^{13} \mathrm{C}\right)$ and phosphoric acid $(85 \%$ in water) $\left({ }^{31} \mathrm{P}\right)$. Chemical shifts are reported in parts per million (ppm) and coupling constants $(J)$ are given in Hertz $(\mathrm{Hz})$. Electrospray ionization mass spectrometry (ESI-MS) was carried out using a Bruker Impact II. Acetonitrile solution was injected directly into the spectrometer at a flow rate of $3 \mu \mathrm{L} \mathrm{min}{ }^{-1}$. Nitrogen was used both as a drying gas and for nebulization with flow rates of approximately $4 \mathrm{~L} / \mathrm{min}$ and a pressure of 0.4 bar. The spectra were collected for one minute and averaged.

Synthesis of bis(6-(diphenylphosphino)acenaphth-5yl)bismuth chloride (2a). $n$-Butyllithium (1.20 mmol, $2.5 \mathrm{M}$ in $n$-hexane) and $N, N, N^{\prime}, N^{\prime}$-tetramethylethylenediamine (139.7 $\mathrm{mg}, 1.20 \mathrm{mmol}$ ) were added at $-78^{\circ} \mathrm{C}$ to a suspension of 5-bromo-6-diphenylphosphino-acenaphthene (500 mg, $1.20 \mathrm{mmol}$ ) in diethyl ether $(15 \mathrm{~mL})$ and stirred for $2 \mathrm{~h}$. The suspension was allowed to warm up to room temperature, stirred for $1 \mathrm{~h}$, and was added at $-78{ }^{\circ} \mathrm{C}$ to a solution of bismuth trichloride $(190.0 \mathrm{mg}, \quad 0.60 \mathrm{mmol})$ and diethyl ether $(15 \mathrm{~mL})$. Temperature of the reaction mixture was slowly raised to room temperature overnight. After settling of the precipitate, the supernatant was decanted and dichloromethane added. Aqueous workup and removal of the solvent via rotary evaporation led to $\mathbf{2 a}$ as pale yellow solid $(470 \mathrm{mg}$, $0.51 \mathrm{mmol}, 85 \%, \mathrm{mp} 192{ }^{\circ} \mathrm{C}$ (dec.)). Single crystals suitable for X-ray diffraction were obtained by slow diffusion of $n$-hexane into a dichloromethane solution at room temperature.

${ }^{1}$ H-NMR (360.3 MHz, $\left.\mathbf{C D}_{2} \mathbf{C l}_{2}\right): \delta=9.16\left(\mathrm{~d},{ }^{3} J\left({ }^{1} \mathrm{H}-{ }^{1} \mathrm{H}\right)\right.$ $=7.0 \mathrm{~Hz}, 2 \mathrm{H}), 7.42\left(\mathrm{~d},{ }^{3} J\left({ }^{1} \mathrm{H}-{ }^{1} \mathrm{H}\right)=7.1 \mathrm{~Hz}, 3 \mathrm{H}\right), 7.31-6.85$ $(\mathrm{m}, 23 \mathrm{H}), 3.44-3.30(\mathrm{~m}, 8 \mathrm{H}) .{ }^{13} \mathbf{C}\left\{{ }^{1} \mathbf{H}\right\}-\mathbf{N M R}$ (90.6 MHz, $\left.\mathbf{C D}_{2} \mathbf{C l}_{2}\right): \delta=152.1$ (s), 147.3 (s), 144.0 (s), 143.0 (d, $\left.{ }^{3} J\left({ }^{31} \mathrm{P}-{ }^{13} \mathrm{C}\right)=10.2 \mathrm{~Hz}\right), 137.2(\mathrm{~s}), 133.6(\mathrm{~d}), 132.7$ (d), 131.0 $\left(\mathrm{d}, J\left({ }^{31} \mathrm{P}-{ }^{13} \mathrm{C}\right)=6.9 \mathrm{~Hz}\right), 129.8(\mathrm{~s}), 128.9\left(\mathrm{~d},{ }^{3} J\left({ }^{31} \mathrm{P}-{ }^{13} \mathrm{C}\right)=4.1\right.$ $\mathrm{Hz}), 125.2(\mathrm{~s}), 120.2\left(\mathrm{~d},{ }^{2} J\left({ }^{31} \mathrm{P}-{ }^{13} \mathrm{C}\right)=2.1 \mathrm{~Hz}\right), 30.9(\mathrm{~s}), 30.7$ (s). ${ }^{31} \mathbf{P}\left\{{ }^{1} \mathbf{H}\right\}$-NMR (145.9 MHz, $\mathbf{C D}_{2} \mathbf{C l}_{2}$ ): $\delta=-20.9$ (s). HRESI MS: $\left(\mathrm{CH}_{2} \mathrm{Cl}_{2} / \mathrm{MeCN} 1: 100\right.$, positive mode): calcd for $\mathrm{C}_{48} \mathrm{H}_{36} \mathrm{P}_{2} \mathrm{Bi}[\mathrm{M}-\mathrm{Cl}]^{+}$, 883.20907; found, 883.20772.

Table 1

Crystal data and structure refinement of $\mathbf{2 a}$ and $\mathbf{3 a}$

\begin{tabular}{|c|c|c|}
\hline & $2 \mathbf{a}$ & $\mathbf{3 a} \cdot \mathrm{CH}_{2} \mathrm{Cl}_{2}$ \\
\hline Formula & $\mathrm{C}_{48} \mathrm{H}_{36} \mathrm{BiClP}_{2}$ & $\mathrm{C}_{73} \mathrm{H}_{56} \mathrm{BiCl}_{2} \mathrm{P}_{3}$ \\
\hline Formula weight, $\mathrm{g} \mathrm{mol}^{-1}$ & 919.14 & 1305.96 \\
\hline Crystal system & triclinic & triclinic \\
\hline Crystal size, $\mathrm{mm}$ & $0.20 \times 0.10 \times 0.10$ & $0.08 \times 0.08 \times 0.06$ \\
\hline Space group & $P \overline{1}$ & $P \overline{1}$ \\
\hline$a, \AA$ & $12.2176(3)$ & $12.7530(4)$ \\
\hline$b, \AA$ & $19.4901(4)$ & $14.4881(4)$ \\
\hline$c, \AA$ & $20.2705(5)$ & $17.8021(6)$ \\
\hline$\alpha,{ }^{\circ}$ & $114.407(1)$ & $74.605(1)$ \\
\hline$\beta,{ }^{\circ}$ & $102.483(1)$ & $79.599(1)$ \\
\hline$\gamma,{ }^{\mathrm{o}}$ & $98.766(1)$ & $64.512(1)$ \\
\hline$V, \AA^{3}$ & $4129.9(2)$ & $2854.3(2)$ \\
\hline$Z\left(Z^{\prime}\right)$ & $4(2)$ & $2(1)$ \\
\hline$\rho_{\text {calcd }}, \mathrm{Mg} \mathrm{m}^{-3}$ & 1.478 & 1.520 \\
\hline $\mathrm{T}, \mathrm{K}$ & 100 & 100 \\
\hline$\mu(\mathrm{Mo} K \alpha), \mathrm{mm}^{-1}$ & 4.443 & 3.312 \\
\hline$F(000)$ & 1816 & 1312 \\
\hline$\theta$ range, deg & 2.32 to 25.50 & 2.61 to 33.19 \\
\hline \multirow[t]{3}{*}{ Index ranges } & $-14 \leq \mathrm{h} \leq 14$ & $-18 \leq \mathrm{h} \leq 19$ \\
\hline & $-23 \leq \mathrm{k} \leq 23$ & $-21 \leq \mathrm{k} \leq 22$ \\
\hline & $-24 \leq 1 \leq 24$ & $-27 \leq 1 \leq 27$ \\
\hline No. of reflns collected & 33470 & 72740 \\
\hline Completeness to $\theta_{\max }$ & $97.4 \%$ & $99.9 \%$ \\
\hline No. indep. Reflns & 14966 & 21891 \\
\hline No. obsd reflns with $(I>2 \sigma(I))$ & 11605 & 18918 \\
\hline No. refined params & 937 & 712 \\
\hline $\operatorname{GooF}\left(F^{2}\right)$ & 0.966 & 1.031 \\
\hline$R_{1}(F)(I>2 \sigma(I))$ & 0.0274 & 0.0325 \\
\hline$w R_{2}\left(F^{2}\right)$ (all data) & 0.0612 & 0.0643 \\
\hline$(\Delta / \sigma)_{\max }$ & 0.004 & 0.005 \\
\hline Largest diff peak/hole, e $\AA^{-3}$ & $2.194 /-0.677$ & $1.832 /-1.182$ \\
\hline CCDC & 1939481 & 1939482 \\
\hline
\end{tabular}


Synthesis of tris((6-(diphenylphosphino)acenaphth-5yl))bismuth (3a). $n$-Butyllithium (2.88 mmol, $2.5 \mathrm{M}$ in $n$-hexane) and $N, N, N^{\prime}, N^{\prime}$-tetramethylethylenediamine $(334.7 \mathrm{mg}, 2.88 \mathrm{mmol})$ were added at $-78^{\circ} \mathrm{C}$ to a suspension of 5-bromo-6diphenylphosphinoacenaphthene $(1.00 \mathrm{~g}, 2.40 \mathrm{mmol})$ in diethyl ether $(50 \mathrm{~mL})$ and stirred for $2 \mathrm{~h}$ at this temperature. The suspension was allowed to warm up to room temperature, stirred for $1 \mathrm{~h}$ and cooled to $-78^{\circ} \mathrm{C}$ again before a solution of bismuth trichloride $(252 \mathrm{mg}, 0.80 \mathrm{mmol})$ in diethyl ether $(15 \mathrm{~mL})$ was added. The reaction mixture was slowly raised to room temperature overnight. The precipitate was filtered, washed with acetonitrile $(3 \times 50 \mathrm{~mL})$, solved in dichloromethane and filtered a second time. Removal of the solvent via rotary evaporation led to 3a as pale yellow solid ( $710 \mathrm{mg}, 0.58 \mathrm{mmol}, 73 \%$, mp $178{ }^{\circ} \mathrm{C}$ (dec.)). Single crystals suitable for X-ray diffraction were obtained by slow diffusion of $n$-hexane into a dichloromethane solution at room temperature.

${ }^{1}$ H-NMR (600.5 MHz, $\left.\mathbf{C D}_{2} \mathbf{C l}_{2}\right): \delta=8.68\left(\mathrm{~d},{ }^{3} J\left({ }^{1} \mathrm{H}-{ }^{1} \mathrm{H}\right)=\right.$ $6.7 \mathrm{~Hz}, 3 \mathrm{H}), 7.24-7.21(\mathrm{~m}, 10 \mathrm{H}), 7.14\left(\mathrm{~d},{ }^{3} J\left({ }^{1} \mathrm{H}^{-1} \mathrm{H}\right)=7.5 \mathrm{~Hz}\right.$, 6H), 7.12-7.09 (m, 4H), 6.99-6.96 (m, 14H), 6.55-6.53 (m, 5H), 3.46-3.29 (m, 12H). ${ }^{13} \mathbf{C}\left\{{ }^{1} \mathbf{H}\right\}-\mathbf{N M R} \quad(\mathbf{1 5 1 . 0} \mathbf{~ M H z}$, $\left.\mathbf{C D}_{2} \mathbf{C l}_{2}\right): \delta=150.2(\mathrm{~s}), 145.7(\mathrm{~s}), 145.2(\mathrm{~s}), 141.5-141.4(\mathrm{~m})$, 138.4-138.3 (m), $137.5\left(\mathrm{~s}, \mathrm{C}_{\mathrm{a}}\right.$ or $\left.\mathrm{C}_{\mathrm{b}}\right), 133.6-133.5(\mathrm{~m}), 132.6$ $132.5(\mathrm{~m}), 128.2(\mathrm{~m}), 128.1(\mathrm{~s}), 127.7(\mathrm{~m}), 127.4(\mathrm{~s}), 123.7$ (s), 119.0 (s), 30.3 (s), 30.1 (s). ${ }^{31} \mathbf{P}\left\{{ }^{1} \mathbf{H}\right\}-N M R$ (243.0 MHz, $\left.\mathbf{C D}_{2} \mathbf{C l}_{2}\right): \delta=-30.6(\mathrm{~s})$. HR-ESI MS $\left(\mathrm{CH}_{2} \mathrm{Cl}_{2} / \mathrm{MeCN} 1: 100\right.$ positive mode): calcd for $\mathrm{C}_{72} \mathrm{H}_{54} \mathrm{BiKP}_{3}[\mathrm{M}+\mathrm{K}]^{+}, 1259.28739$; found, 1259.28742.

X-ray crystallography. Intensity data of $\mathbf{2 a}$ and $\mathbf{3 a}$ was collected on a Bruker Venture D8 diffractometer with graphite-monochromated Mo-K $\alpha(0.7107 \AA)$ radiation. The structure was solved by direct methods and difference Fourier synthesis with subsequent Full-matrix least-squares refinements on $F^{2}$, using all data. ${ }^{21}$ All non-hydrogen atoms were refined using anisotropic displacement parameters. Hydrogen atoms attached to carbon atoms were included in geometrically calculated positions using a riding model. Strongly disordered THF molecules in the crystal lattice of $\mathbf{2 a}$ were accounted for using the SQUEZZE routine. ${ }^{22}$ Crystal and refinement data are collected in Table 1. Figures were created using DIAMOND. ${ }^{23}$ Crystallographic data for the structural analysis has been deposited with the Cambridge Crystallographic Data Centre. Copies of this information may be obtained free of charge from The Director, CCDC, 12 Union Road, Cambridge CB2 1EZ, UK (Fax: +44-1223336033; e-mail: deposit@ccdc.cam.ac.uk or http://www.ccdc.cam.ac.uk).

\section{CONCLUSIONS}

We present the synthesis of the P-stabilized diarylbismuthchloride $\mathbf{2 a}$ and the triarylbismuth species 3a along with its structural properties derived by single crystal diffraction measurements and NMR spectroscopy. The synthetic potential of both compounds for the preparation of transition metal complexes is currently under investigation.

\section{REFERENCES}

1. C. I. Raț, C. Silvestru and H. J. Breunig, Coord. Chem. Rev., 2013, 257, 818-879 and references cited therein.

2. I. Urbanová, R. Jambor, A. Růžička, R. Jirásko and L. Dostál, Dalton Trans., 2014, 43, 505-512.

3. I. Vránová, R. Jambor, A. Růžička, R. Jirásko and L. Dostál, Organometallics, 2015, 34, 534-541.

4. I. Vránová, M. Alonso, R. Lo, R. Sedlák, R. Jambor, A Růžička, F. De Proft, P. Hobza and L. Dostál, Chem. Eur. $J ., 2015,21,16917-16928$.

5. M. Olaru, M. G. Nema, A. Soran, H. J. Breunig and C. Silvestru, Dalton Trans., 2016, 45, 9419-9428.

6. R. Kannan, S. Kumar, A. P. Andrews, E. D. Jemmis and A. Venugopal, Inorg. Chem., 2017, 56, 9391-9395.

7. I. Chircâ, C. Silvestru, H. J. Breunig and C. I. Raț, Inorg. Chim. Acta., 2018, 475, 155-160.

8. I. Vránová, T. Dušková, M. Erben, R. Jambor, A. Růžička and L. Dostál, J. Organomet. Chem., 2018, 863, 15-20.

9. T.-P. Lin, I.-S. Ke and F. P. Gabbai, Angew. Chem. Int. Ed., 2012, 51, 4985-4988.

10. C. Tschersich, C. Limberg, S. Roggan, C. Herwig, N. Ernsting, S. Kovalenko and S. Mebs, Angew. Chem. Int. Ed., 2012, 51, 4989-4992.

11. W. Guan, S. Yamabe and S. Sakaki, Dalton Trans., 2013, 42, 8717-8728.

12. C. Tschersich, B. Braun, C. Herwig and C. Limberg, $J$. Organomet. Chem., 2015, 784, 62-68.

13. C. Tschersich, B. Braun, C. Herwig and C. Limberg, Organometallics, 2015, 34, 3782-3787.

14. C. Tschersich, S. Hoof, N. Frank, C. Herwig and C. Limberg, Inorg. Chem., 2016, 55, 1837-1842.

15. R. Mokrai, J. Barrett, D. C. Apperley, A. S. Batsanov, Z. Benkö and D. Heift, Chem. Eur. J., 2019, 25, 4017-4024.

16. E. Hupf, E. Lork, S. Mebs, L. Chęcińska and J. Beckmann, Organometallics, 2014, 33, 7247-7259.

17. S. Furan, E. Hupf, J. Boidal, J. Brünig, E. Lork, S. Mebs and J. Beckmann, Dalton Trans., 2019, 48, 4504-4513.

18. D. Duvinage, P. Bottke, M. Wark, E. Lork, S. Mebs and J. Beckmann, Eur. J. Inorg. Chem., 2019, 712-720.

19. B. A. Chalmers, C. B. E. Meigh, P. S. Nejman, M. Bühl, T. Lébl, J. D. Woollins, A. M. Z. Slawin, P. Kilian, Inorg. Chem., 2016, 55, 7117-7125.

20. J. Beckmann, T. G. Do, S. Grabowsky, E. Hupf, E. Lork and S. Mebs, Z. Anorg. Allgem. Chem., 2013, 639, 2233 2249.

21. O. V. Dolomanov, L. J. Bourhis, R. J. Gildea, J. A. K. Howard and H. Puschmann, J. Appl. Cryst., 2009, 42, 339-341.

22. A. Spek, J. Appl. Cryst., 2003, 36, 7-13.

23. K. Brandenburg, DIAMOND version 3.2i, Crystal Impact GbR, Bonn Germany 2012. 